\title{
PENGARUH LATIHAN IMAGERY COCNITIVE SPECIFIC TERHADAP AKURASI SHOOTING MENGGUNAKAN AWALAN DALAM PERMAINAN BOLATANGAN
}

\author{
Dyas Andry Prasetyo ${ }^{1}$, Shally Nordiansyah ${ }^{2}$ \\ 1,2 Program Studi Pendidikan Jasmani Kesehatan dan Rekreasi, STKIP PGRI Sumenep \\ E-mail: dyasandry@stkippgrisumenep.ac.id1', shallynordiansyah@stkippgrisumenep.ac.id² \\ DOI: https://doi.org/10.36526/kejaora.v5i2.1004
}

\begin{abstract}
ABSTRAK
Latihan Imagery Cocnitive Specific merupakan salah satu bentuk latihan khusus yang dapat mempengaruhi mental, teknik, maupun taktik. Latihan ini diterapkan guna mengatasi permasalahan mental dalam sebuah pertandingan/permainan agar atlet dapat melewati tahap depresi. Tujuan penelitian ini adalah untuk menguji dan mengetahui pengaruh latihan Imagery Cocnitive Specific terhadap akurasi shooting dengan awalan dalam permainan bolatangan. Metode penelitian ini menggunakan jenis penelitian Pre Experimental Design dengan jenis One Group Pretest-Posttest Design. Sampel penelitian berjumlah 15 orang yang ditentukan menggunakan teknik Purposive Sampling. Pengumpulan data diperoleh dengan cara melakukan tes shooting dengan awalan yaitu Pre-test dan Post-test. Instrumen yang digunakan adalah latihan Imagery Cocnitive Specific. Teknik analisis data menggunakan rumus Prosentase dengan bantuan aplikasi Software Statistical Product and Service Solution (SPSS) version 18.0. Pemberian perlakuan latihan Imagery Cocnitive Specific selama 8 kali pertemuan memberikan pengaruh terhadap akurasi shooting, yaitu sebesar 29,57\% yang dapat disimpulkan bahwa latihan Imagery Cocnitive Specific dapat meningkatkan akurasi shooting dalam permainan bolatangan.
\end{abstract}

Kata Kunci: Latihan Imagery, Imagery Cocnitive Specific, Shooting, Bolatangan.

\section{PENDAHULUAN}

Perkembangan dunia olahraga dewasa ini menuntut banyak pihak untuk terus meningkatkan mutu dan prestasi baik di ranah manajemen, pelatih, maupun atlet agar selalu siap dan kompetitif dalam menghadapi setiap tantangan yang ada. Tuntutan tersebut bukan semata-mata datang dari satu atau dua pihak melainkan lebih kepada antusiasme pelaku olahraga untuk terus menjadi yang terbaik dan berusaha meningkatkan serta mempertahankan prestasi yang telah dicapai. Kecenderungan inilah yang membuat dunia olahraga terlihat hidup dan terus berjalan maju hingga saat ini.

Prestasi merupakan sebuah puncak dari usaha pelaku olahraga sebagai tolak ukur keberhasilan, oleh karena itu untuk mencapai dan mempertahankan prestasi, perlu adanya sebuah program khusus yang diterapkan dalam bentuk latihan-latihan dan dilakukan secara intensif. Program latihan disusun sesuai dengan karakteristik atlet agar hasil yang dicapai sesuai dengan harapan/tujuan dari latihan itu sendiri. Keberagaman latihan menjadi dapat diterapkan saat menyusun program yang tentunya harus mengaju pada apa yang ingin dicapai, dengan kata lain pemilihan bentuk latihan harus benar-benar diperhatikan agar tidak salah konsep saat melakukan latihan tersebut. Berdasarkan prinsipnya, latihan merupakan suatu proses perubahan ke arah yang lebih baik, yaitu untuk meningkatkan kualitas fisik, kemampuan fungsional peralatan tubuh, dan kualitas psikis anak latih (Sukadiyanto, 2011). Dari teori ini sudah sangat jelas bahwa latihan dapat diberikan untuk mencapai ketahanan fisik maupun mental.

Salah satu bentuk latihan yang biasa digunakan adalah latihan imagery. Imagery menurut teori Visual Motor Behavior oleh (Hartona, 2010) adalah "proses holistic yang meliputi reintegrasi pengalaman secara lengkap, termasuk di dalamnya rangsang 
Jurnal Kejaora: Jurnal Kesehatan Jasmani dan Olah Raga

ISSN: 2541-5042 (Online)

ISSN: 2503-2976 (Print)

Volume 5 Nomor 2, Edisi November 2020

penglihatan, pendengaran, rangsang taktil (sentuhan, perabaan dan tekanan), emosional, dan kinestetik." Dengan kata lain, latihan imagery sangat efektif digunakan untuk memperbaiki teknik maupun mental atlet yang mengalami kemunduran performa. Salah satu latihan imagery yang sering dilakukan adalah Cocnitive Specifik yang pernah diterapkan pada latihan bolatangan di STKIP PGRI Sumenep, akan tetapi tidak dilakukan secara intensif. Latihan Imagery Cocnitive Specific khusus digunakan untuk meningkatkan keterampilan olahraga yang spesifik, jadi sangat sesuai apabila diterapkan pada cabang olahraga kompetitif seperti bolatangan mengingat olahraga ini memiliki tempo yang cepat dan cenderung terlibat body contact antar pemain. Olahraga bolatangan merupakan salah satu olahraga yang sampai saat ini dapat ditelusuri kebenaran sejarahnya dan telah berusia sangat tua. Sebuah fakta yang meyakinkan telah menunjukkan bahwa seorang laki-laki akan senantiasa lebih mahir menggunakan tangan daripada kakinya, sebagaimana telah diklaim oleh sejarawan olahraga terkenal, bahwa ia memainkan bolatangan jauh lebih awal daripada sepakbola (Susanto, 2004). Bolatangan adalah olahraga beregu dimana dua regu dengan masing-masing 7 pemain 6 pemain dan 1 penjaga gawang) berusaha memasukkan sebuah bola ke gawang lawan (Supriadi, 2010).

Imagery sering disebut dengan guided imagery, visualization, latihan mental, atau self hypnosis. Imagery adalah teknik yang biasa digunakan oleh psikolog olahraga untuk membantu seseorang memvisualisasikan atau melatih mental berkaitan dengan kegiatan yang akan dilakukan (Setyawati, 2014). Bentuk latihan menurut (Komarudin, 2015) diklasifikasikan menjadi beberapa macam yang meliputi: 1) Cocnitive Specific (CS), 2) Cocnitive General (CG), 3) Motivational Specific (MS), 4) Motivational General Arousal (MGA), dan 5) Motivational General Mastery (MGM). Latihan Imagery Cocnitive Specific yang pernah diberikan pada tim bolatangan putra STKIP PGRI Sumenep berupa rangsang motivasi dengan menerapkan teknik dasar shooting dan dilakukan secara langsung. Kemampuan

Lemparan yang baik dari seorang pemain akan memberikan dampak yang signifikan bagi tim dalam memenangkan sebuah pertandingan (Lusiana, 2015). Secara kasat mata, latihan ini memberikan perubahan baik pada teknik maupun akurasi tembakan, akan tetapi belum diketahui secara pasti pengaruh Latihan Imagery Cocnitive Specific apabila dilakukan secara intensif dan diukur berdasarkan instrument akurasi shooting. Latihan ini sangat sesuai diterapkan di STKIP PGRI Sumenep mengingat intensitas latihan tim bolatangan putra kurang maksimal dan cenderung dapat dikatakan jarang latihan. Dari fenomena di atas, maka peneliti berasumsi bahwa penelitian ini penting untuk dikaji agar nantinya dapat dijadikan patokan dalam melatih dan mengatasi kelemahan teknik dan akurasi dalam permainan bolatangan, dengan cara mencari tahu pengaruh yang diberikan Latihan Imagery Cocnitive Specific terhadap akurasi shooting dalam permainan bolatangan.

\section{METODE}

Peneliti menggunakan jenis penelitian Pre Experimental Design dengan jenis One Group Pretest-Posttest Design, dengan $\mathrm{X}_{1}$--$Y$--- $X_{2}$ (Sugiyono, 2011). Sampel penelitian menggunakan atlet bolatangan putra STKIP PGRI Sumenep sebanyak 15 orang dan dipilih menggunakan teknik Purposive Sampling yang disesuaikan dengan kebutuhan penelitian. Instrumen dalam penelitian ini menggunakan Treatment Imagery Cocnitive Specific and Test.

Teknik pengumpulan data pada penelitian ini menggunakan tes yang nantinya hasil dari tes tersebut dianalisis dan dideskripsikan ke dalam hasil dan pembahasan penelitian. Berikut cara mengambil data menggunakan tes akurasi shooting bolatangan sebagai berikut: 1) Testee berdiri dibelakang garis yang bertanda $X, 2)$ Jarak shooting dengan gawang sejauh 7 meter, 3) Pandangan lurus ke depan, 4) Posisi kaki sebelah diri berada di belakang garis,dan kaki kanan selangkah di belakang, 5) Angkat tangan kanan sekitar $90^{\circ}$ dari badan, dan tangan kiri sebagai penyeimbang, 6) Kemudian tarik tangan kanan ke belakang sampai badan berbalik $45^{\circ}$ ke samping, 7) 
Jurnal Kejaora: Jurnal Kesehatan Jasmani dan Olah Raga

ISSN: 2541-5042 (Online)

ISSN: 2503-2976 (Print)

Volume 5 Nomor 2, Edisi November 2020

Ayunkan tangan kanan ke depan, kemudian lemparkan bola dengan sekuat tenaga ke arah yang diinginkan, 8) Gerak lanjutan (setelah bola terlepas dari tangan, kaki kanan boleh melangkah ke depan sebagai penyeimbang badan), dan 9) Shooting yang baik apabila bola mengarah tepat pada target yang dituju dengan akurat. Teknik analisis data menggunakan rumus Prosentase dengan bantuan aplikasi Software Statistical Product and Service Solution (SPSS) version 18.0.

\section{HASIL DAN PEMBAHASAN}

Pengambilan data pretest dimulai pada Selasa, 9 Juni 2020, sedangkan untuk posttest dilaksanakan pada Kamis, 9 Juli 2020. Pemberian perlakuan (treatment) dilaksanakan sebanyak 8 kali pertemuan, dengan frekuensi 2 kali dalam satu Minggu. Hasil pretest dan posttest disajikan dalam tabel 4.1 sebagai berikut:

Tabel 1. Hasil Akurasi Shooting Dengan Awalan

\begin{tabular}{ccccc}
\hline \multirow{2}{*}{ No } & \multicolumn{2}{c}{ Jumlah } & \multicolumn{2}{c}{ Rata - rata } \\
\cline { 2 - 5 } & Pretest & Posttest & Pretest & Posttest \\
\hline 1 & 8 & 12 & 2,67 & 4 \\
\hline 2 & 8 & 14 & 2,67 & 4,67 \\
\hline 3 & 10 & 13 & 3,33 & 4,33 \\
\hline 4 & 9 & 12 & 3 & 4 \\
\hline 5 & 9 & 10 & 3 & 3,33 \\
\hline 6 & 7 & 13 & 2,33 & 4,33 \\
\hline 7 & 7 & 12 & 2,33 & 4 \\
\hline 8 & 7 & 10 & 2,33 & 3,33 \\
\hline 9 & 8 & 12 & 2,67 & 4 \\
\hline 10 & 6 & 13 & 2 & 4,33 \\
\hline 11 & 7 & 12 & 2,33 & 4 \\
\hline 12 & 7 & 11 & 2,33 & 3,67 \\
\hline 13 & 8 & 11 & 2,67 & 3,67 \\
\hline 14 & 8 & 12 & 2,67 & 4,00 \\
\hline 15 & 10 & 11 & 3,33 & 4,33 \\
\hline & & & & \\
\hline
\end{tabular}

Berdasarkan tabel 1 di atas, diperoleh hasil analisis statistik deskriptif pretestposttest akurasi Shooting dengan awalan yaitu Pretest nilai minimal $=2,00$, nilai maksimal $=3,33$, rata-rata $($ mean $)=2,64$,

dengan simpang baku (std. Deviation) $=0,38$, sedangkan untuk Posttest nilai minimal $=$ 3,33 , nilai maksimal $=4,67$, rata-rata (mean) $=3,99$, dengan simpang baku (std. Deviation) $=0,37$.

Tabel 2. Deskriptif Statistik

\begin{tabular}{lrr}
\hline Statistik & Pretest & \multicolumn{1}{c}{ Posttest } \\
\hline $\mathrm{N}$ & 15 & 15 \\
\hline Mean & 2,6440 & 3,9993 \\
\hline Median & 2,6700 & 4,0000 \\
\hline Mode & 2,33 & 4,00 \\
\hline Std, &, 38783 &, 37797 \\
Deviation & 2,00 & 3,33 \\
\hline Minimum & 3,33 & 4,67 \\
\hline Maximum & 39,69 & 59,99 \\
\hline Sum & & \\
\hline
\end{tabular}

Berdasarkan deskriptif pada tabel 2 tersebut di atas, pretest dan posttest akurasi shooting atlet bolatangan putra STKIP PGRI Sumenep dapat disajikan pada gambar 4.1 sebagai berikut:

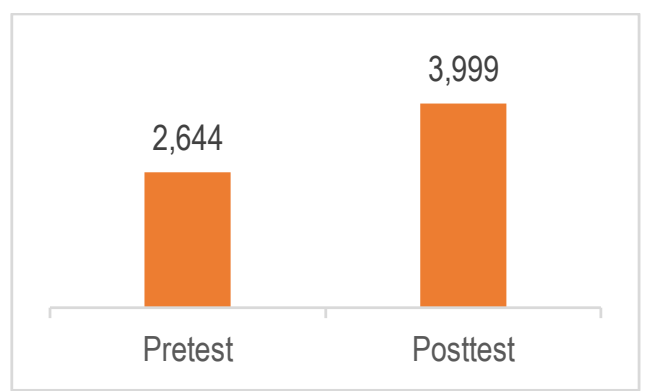

Diagram 1. Akurasi Shooting Dengan Awalan

Berdasarkan hasil uji normalitas dimaksudkan untuk mengetahui apakah variabel-variabel dalam penelitian mempunyai sebaran distribusi normal atau tidak. Penghitungan uji normalitas ini menggunakan rumus Kolmogorov- Smirnov $Z$, dengan pengolahan menggunakan bantuan komputer program SPSS 22 sebagai berikut:

Tabel 3. Uji Normalitas

\begin{tabular}{rrr}
\hline Kelompok & $\mathrm{P}$ & Keterangan \\
\hline Pretest & 0,073 & Normal \\
\hline Posttest & 0,063 & Normal \\
\hline
\end{tabular}


Jurnal Kejaora: Jurnal Kesehatan Jasmani dan Olah Raga

ISSN: 2541-5042 (Online)

ISSN: 2503-2976 (Print)

Volume 5 Nomor 2, Edisi November 2020

Dari hasil tabel 3 di atas dapat dilihat bahwa semua data memiliki nilai $p$ (Sig.) > 0.05 , maka data berdistribusi normal. Karena semua data berdistribusi normal maka analisis dapat dilanjutkan untuk uji hipotesis.

Uji-t digunakan untuk menguji hipotesis yang berbunyi "ada pengaruh yang signifikan latihan Imagery Cocnitive Specific terhadap peningkatan akurasi shooting dengan awalan dalam permainan bolatangan", berdasarkan hasil pre-test dan

post-test. Apabila hasil analisis menunjukkan perbedaan yang signifikan maka latihan Imagery Cocnitive Specific memberikan pengaruh terhadap peningkatan akurasi shooting. Kesimpulan penelitian dinyatakan signifikan jika nilai $t$ hitung $>t$ tabel dan nilai sig lebih kecil dari $0,05(\mathrm{Sig}<0.05)$. Berdasarkan hasil analisis diperoleh data pada tabel 4.4 sebagai berikut. Hasil selengkapnya disajikan pada lampiran.

Tabel 4. Uji-t Ketepatan Shooting

\begin{tabular}{|c|c|c|c|c|c|c|}
\hline \multirow{2}{*}{ Kelompok } & \multirow{2}{*}{ Rata-rata } & \multicolumn{5}{|c|}{ t-test for Equality of means } \\
\hline & & tht & $\mathrm{t} t \mathrm{tb}$ & Sig. & Selisih & $\%$ \\
\hline Pretest & 7,9333 & \multirow{2}{*}{8,909} & \multirow{2}{*}{2,145} & \multirow{2}{*}{0,000} & \multirow{2}{*}{3,9334} & \multirow{2}{*}{$29,57 \%$} \\
\hline Posttest & 11,8667 & & & & & \\
\hline
\end{tabular}

Dari hasil uji-t dapat dilihat bahwa $t$ hitung 8,909 dan $t$ tabel 2,145 (df 14) dengan nilai signifikansi $p$ sebesar 0,000 . Oleh karena $t_{\text {hitung }} 8,909>$ t tabel 2,145 , dan nilai signifikansi $0,000<0,05$, maka hasil ini menunjukkan terdapat perbedaan yang signifikan. Dengan demikian hipotesis alternatif $(\mathrm{Ha})$ yang berbunyi "ada pengaruh yang signifikan antara latihan Imagery Cocnitive Specific terhadap akurasi shooting dengan awalan dalam permainan bolatangan", diterima. Artinya latihan tersebut memberikan pengaruh yang signifikan terhadap peningkatan akurasi shooting. Dari data pretest memiliki rata - rata 2,64, selanjutnya pada saat posttest rata -rata mencapai 3,99. Besarnya peningkatan akurasi shooting tersebut dapat dilihat dari perbedaan nilai rata-rata yaitu sebesar 1,35, dengan prosentase sebesar $29,57 \%$.

Berdasarkan analisis data di atas, diperoleh peningkatan yang signifikan terhadap kelompok yang diteliti. Pemberian perlakuan latihan Imagery Cocnitive Specific selama 8 kali pertemuan memberikan pengaruh terhadap akurasi shooting, yaitu sebesar $29,57 \%$. Hal tersebut sesuai dengan teori bahwa "pelatihan imagery bertujuan untuk meningkatkan kemampuan psikologis atlet dilakukan sebanyak 5 sampai 6 kali pertemuan" (Sukamto, 2013).

Metode latihan imagery antara lain memiliki keunggulan, bentuk latihan ketepatan shooting dalam bolatangan yang disajikan mirip atau menyerupai dengan situasi dan kondisi pada saat terjadi shooting sesungguhnya. Selain itu dalam metode latihan imagery merupakan bagian integral dari keseluruhan keterampilan psikologis. Ketika atlet membayangkan atau memvisualisasikan secara gamblang saat sedang latihan dan membayangkan dirinya menunjukkan penampilan sempurna.

$\mathrm{Hal}$ ini sependapat dengan teori (Sukadiyanto, 2011) bahwa "latihan imagery sangat efektif untuk meningkatkan performa atlet, bahkan $90-97 \%$ atlet elit pun menggunakan latihan imagery karena latihan tersebut sangat bermanfaat untuk meningkatkan performanya". Atlet melakukan latihan imagery dengan berbagai tujuan, ada yang berlatih untuk tujuan belajar keterampilan, mengembangkan strategi, mempersiapkan mental sebelum kompetisi, mengembangkan keterampilan mental, mangatasi stres dan rintangan dalam olahraga baik itu cedera, latihan berat, dan gangguan- gangguan lainnya.

Berdasar pada bahasan di atas, latihan imagery khususnya Imagery Cocnitive Specific memiliki pengaruh signifikan terhadap akurasi shooting, dimana yang sudah dijelaskan bahwa "Menembak merupakan suatu usaha/tindakan terpenting dalam permainan bolatangan untuk memasukkan bola ke gawang lawan" 
Jurnal Kejaora: Jurnal Kesehatan Jasmani dan Olah Raga

ISSN: 2541-5042 (Online)

ISSN: 2503-2976 (Print)

Volume 5 Nomor 2, Edisi November 2020

(Prasetyo, 2018). Pada saat melakukan shooting, seorang pemain harus fokus pada target yang akan dituju dan berkonsentrasi agar tembakan yang dilakukan tepat sasaran. dan apabila shooting dalam bolatangan tersebut tidak mengenai target / tidak masuk dalam gawang dapat berpengaruh terhadap kemenangan tim. Oleh karena itu latihan imagery dapat membantu pelatih dan tim putra STKIP PGRI Sumenep untuk bisa memperbaiki keselahan - kesalahan shooting yang sering dilakukan dalam pertandingan.

\section{KESIMPULAN}

Bedasarkan hasil analisis statistik deskriptif pretest - posttest akurasi Shooting dengan awalan dalam permainan bolatangan, dapat disimpulkan bahwa latihan Imagery Cocnitive Specific dapat meningkatkan akurasi shooting dalam permainan bolatangan. Hal ini dapat dibenarkan dengan data yang sudah dijabarkan pada bab sebelumnya bahwa uji normalitas semua data berdistribusi normal. Kemudian hasil uji $t$ ditemukan terdapat perbedaan yang sangat signifikan.

Apabila merujuk pada beberapa teori yang sudah dijelaskan pada bab sebelumnya, maka temuan dalam penelitian ini sejalan, artinya latihan Imagery Cocnitive Specific memang benar-benar memiliki pengaruh yang signifikan terhadap peningkatan akurasi shooting dalam permainan bolatangan dengan prosentase peningkatan sebesar $29,57 \%$.

\section{UCAPAN TERIMAKASIH}

Penelitian ini dibiayai oleh DRPM RISTEKDIKTI berdasarkan Surat Keputusan Nomor 083/SP2HL/LT/DRPM/2020 tanggal 09 Maret 2020 tentang Penetapan Pemenang Hibah Penelitian Dosen Pemula Tahun Anggaran 2019. Terimakasih kami sampaikan sehingga penelitian ini dapat dilaksanakan dan semoga nantinya hasil penelitian ini dapat bermanfaat.

\section{DAFTAR PUSTAKA}

Hartona, S. (2010). Mental Imagery Tinjauan dari Segi Filsafat, IImu-IImu Kognitif dan Neurologis. Unesa Press.

Komarudin. (2015). Psikologi Olahraga. PT. Remja Rosdakarya.

Lusiana. (2015). Faktor Pengaruh Kemampuan Lemparan (Shooting) Pada Atlet Handball Putri Jawa Tengah. Journal of Physical Education Health and Sport, 2(2), 65-68. https://doi.org/10.15294/jpehs.v2i2.45 89

Prasetyo, D. A. (2018). buku ajar bolatangan. In wineka media. Wineka Media.

Setyawati, H. (2014). Strategi Intervensi Peningkatan Rasa Percaya Diri Melalui Imagery Training Pada Atlet Wushu Jawa Tengah. Journal of Physical Education Health and Sport, 1(1), $\quad$ 48-59. https://doi.org/10.15294/jpehs.v111.30 12

Sugiyono. (2011). Statistik Untuk Penelitian. Alfabeta.

Sukadiyanto. (2011). Pengantar Teori dan Metodologi Melatih Fisik. CV. Lubuk Agung.

Sukamto. (2013). Pengaruh Latihan Imagery Terhadap Peningkatan Keterampilan Lay Up Shoot Permainan Bola Basket Siswa Peserta Ekstrakurikulerbolabasketsma $N 1$ Bantul.

Supriadi, D. (2010). Peraturan permainan Bola Tangan. STKIP Pasundan Cmahi.

Susanto, E. (2004). Diktat Pembelajaran Dasar Gerak Bolatangan. Tersedia: Staff. Uny. Ac. Id/Dosen/e RnawanSusanto-Mpd.[24 Februari 2017]. 